DOI:10.2478/rrlm-2019-0022

\title{
Simultaneous FLT3, NPM1 and DNMT3A mutations in adult patients with acute myeloid leukemia - case study
}

Florin Tripon $^{1 *}$, George Andrei Crauciuc ${ }^{1}$, Valeriu George Moldovan ${ }^{1}$, Alina Bogliș ${ }^{1}$, István Jr Benedek ${ }^{1}$, Erzsébet Lázár ${ }^{1}$, Claudia Bănescu

1. University of Medicine, Pharmacy, Science and Technology of Târgu Mureș, Romania

2. Genetics Laboratory-Center for Advanced Medical and Pharmaceutical Research of the University of Medicine, Pharmacy, Science and Technology of Târgu Mureș, Romania; Genetics Department of the Clinical and Emergency County Hospital from Târgu Mureș, Romania

\begin{abstract}
Background: Nowadays, cytogenetics and molecular genetics, but not only, are mandatory in acute myeloid leukemia (AML) management, as a consequence of their impact on AML pathogenesis, classification, risk-stratification, prognosis and treatment. Objective: The aim of our study was to present our algorithm for the analysis of copy number changes, aneuploidies and somatic mutations focusing on a rare AML case positive for four somatic mutations. Methods: Cytogenetic analysis, Multiplex Ligationdependent Probe Amplification (MLPA) analysis, somatic mutation analysis (for FLT3 ITD, FLT3 D835, DNMT3A R882 and NPM1 c.863_864ins) by using several PCR techniques and also next-generation sequencing (NGS) analysis were performed. Results: Cytogenetic analysis did not reveal structural or numerical chromosomal anomalies. The patient's DNA showed no copy number changes or aberrations (CNAs) following the MLPA analysis. By using several molecular technologies we found four mutations: FLT3-ITD, FLT3 D835 (c.2504A>T, D835V), DNMT3A R882C, and NPM1 c.863_864insTCTG. Challenges, benefits, applications and the limitations of each molecular technique used for the investigation of the mentioned mutation, and not only, are also described. Conclusion: All these techniques can be useful in the diagnosis of AML patients, each of them covering the limits of the other technique. New strategies for a positive, fast, accurate and reliable diagnosis are mandatory in cases with $A M L$.
\end{abstract}

Keywords: acute myeloid leukemia, MLPA, NGS, FLT3, DNMT3A, NPM1

Received: $31^{\text {st }}$ December 2018; Accepted: $18^{\text {th }}$ March 2019; Published: $3^{\text {rd }}$ April 2019

\section{Introduction}

Acute myeloid leukemia (AML) is one of the myeloid neoplasms characterized by immature progenitors proliferation and accumulation [1]. As a result of the poor survival rate of AML patients, treatment resistance, frequent relapses and numerous secondary conditions of AML, several studies focused on this disease in order to extend the existing knowledge $[2,3]$. Nowadays, cytogenetics and molecular genetics, but not only, are mandatory in AML management, as a consequence of their clinical impact [2-5].

Several chromosomal rearrangements and aneu-

\footnotetext{
*Corresponding author: Florin Tripon, University of Medicine, Pharmacy, Science and Technology of Târgu Mureș, Romania E-mail: tripon.florin.2010@gmail.com
} 
ploidies were included in the latest AML classification [6] and also in the 2017 version of the European LeukemiaNet (ELN) Risk Stratification by Genetics [7]. Some of them may be identified by cytogenetic investigation while others need molecular approaches.

Banding cytogenetic and fluorescent in situ hybridization (FISH) were routinely used for the investigation of chromosomal abnormalities in leukemia. Considering that cytogenetic analysis has a low resolution and FISH investigates only large and common lesions, a multiplex assay, namely Multiplex Ligation-dependent Probe Amplification (MLPA) was proposed for the detection of chromosomal aberrations, represented by deletions or duplications that may lead to copy number alterations in genomic DNA. MLPA is a fast, useful and cost-effective technique that can be used in order to detect copy number aberrations (CNAs) and also aneuploidies for leukemia patients, but not only [8-10].

In addition to the chromosomal rearrangements and aneuploidies, several somatically acquired mutations are described in AML patients, most of them being involved in the evolution of AML, but still, currently, few of them are included in the AML classification and ELN risk-stratification [6,7]. Briefly, according to the moment during leukemogenesis, two groups of somatically acquired mutations were described: early acquired mutations [such as DNA methyltransferase $3 \mathrm{~A}$ gene $(D N M T 3 A)$ etc.] and late acquired mutations [such as FMS-like Tyrosine Kinase 3 (FLT3), Nucleophospmin 1 (NPM1) genes, etc.] $[2,3]$. The consequences of FLT3 and NPM1 mutations are well-known [1-7, 11]. Early acquired mutations remain a continuous challenge for AML because these may persist after therapy, leading to clonal expansion during hematologic remission, and eventually to relapse [3].

Analysis of these mutations requires the choice of the most effective, specific and sensitive molecular techniques taking into account the type of mutation, its size and locus, percentage of the mutant clone, and of course the available infrastructure.

Here, we present a rare AML case with four somatic mutations, identified according to our algorithm for the analysis of CNAs, aneuploidies and somatic mutations.

\section{Material and Methods}

\section{Clinical report}

We investigated a 64-year-old male patient diagnosed with AML classified as M1 according to the French-American-British classification. Patient complaints were: asthenia, fatigability, loss of appetite and weight loss (10 kilograms in 3 weeks).

Flow cytometry immunophenotyping revealed the presence of $33.8 \%$ myeloid elements, $4 \%$ lymphocytes, $2.5 \%$ erythroblasts, $35 \%$ atypical monocytes [positive for CD33(58\%), CD15, CD11b(83\%), CD11c, CD64, CD14(14.5\%), CD38, CD123, CD4, HLA-DR and negative for CD16, CD36, CD34, CD117] and 24\% myeloblasts [positive for CD13(85\%), CD33, CD15(3\%), CD11c(50\%), CD64(18.5\%), HLA-DR(var), CD34(5\%), CD117, CD38, CD123, CD7(75\%), CD4(18.5\%) and negative for CD3, CD22, CD10, CD14, CD16, CD36, CD11b].

The treatment with low dose of Cytosar was initiated and peripheral blood and bone marrow were collected and sent to the Genetics Department.

The workflow of investigation performed in AML cases is based on recommendations of Döhner et al. [7] and is as follow: cytogenetic, gene mutations analysis (including FLT3, NPM1, TP53, RUNX1), additional procedures on diagnosis: MLPA. Molecular investigation was started in parallel with cytogenetic analysis in order to have the results in a timely manner. 


\section{Cytogenetic analysis}

Cytogenetic analysis was performed from bone marrow and peripheral blood. GTG-banding (G-bands by Trypsin and Giemsa) was performed and described according to the International System for Human Cytogenetic Nomenclature (ISCN) 2013.

\section{Somatic mutation analysis}

FLT3-ITD, FLT3-D835 (c.2503 G>C/A/T; c. $2504 \mathrm{~A}>\mathrm{C} / \mathrm{T}$; c.2505 T>A/G), DNMT3A (codon R882) and NPMI (c.863_864ins) mutations were analyzed using specific primers and the PCR, RFLP-PCR and ARMS-PCR techniques as previously described [12-14]. In order to confirm and quantify the presence of the mutant clone, we performed fragment analysis for FLT3-ITD and NPM1 mutations, as previously reported [15], on an Applied Biosystems 3500 Genetic Analyzer. The detailed protocols used with locally adapted and optimized conditions are mentioned in Table I. In order to confirm the mutations found by RFPL-PCR (FLT3-D835 and $D N M T 3 A$ ), we performed sequencing as previously described [16].

\section{Next-generation sequencing analysis (NGS)}

NGS analysis was performed using the Ion Proton system and Ion AmpliSeq ${ }^{\mathrm{TM}}$ AML Research Panel (ThermoFisher Scientific), a four-pool panel containing 237 amplicons from 19 different genes involved in AML. Interested loci from different genes such as GATA2, KRAS, NRAS, IDH1, IDH2, ASXL1, TET2, CEBPA, RUNX1, $T P 53$, and others were analyzed in order to find different mutation types. Ion Reporter ${ }^{\mathrm{TM}}$ Software (ThermoFisher Scientific) was used to analyze the results.

\section{MLPA analysis}

The patient's DNA was extracted from peripheral blood (PureLink GenomicDNA, ThermoFisher). In order to detect possible aneuploidies, as pre- viously described [10], as well as subtelomeric CNAs and the most common and clinically significant CNAs in AML, we performed MLPA analysis using SALSA MLPA P036, P070 and P377 probemixes (MRC-Holland). After capillary electrophoresis (Applied Biosystems 3500 Genetic Analyzer), Coffalyser.net software was used to interpret the results using three reference DNA samples (without CNAs).

\section{Results}

Cytogenetic analysis did not reveal structural or numerical chromosomal anomalies.

Somatic mutation analysis was performed for FLT3-ITD (PCR), FLT3-D835 (RFLP-PCR), NPM1 (ARMS-PCR) and DNMT3A (RFLPPCR), the patient being heterozygous for FLT3ITD and D835, NPM1 and DNMT3A R882C. The specific inserted nucleotides (A-D mutation type) were not determined by ARMS-PCR technique due to possible cross-reactions between the different NPM1 primers used (electrophoresis results in Figure 1).

We continued with confirming our somatic mutation results using different techniques. Fragment analysis was performed for FLT3-ITD and NPM1 mutations and sequencing for FLT3-D835 and DNMT3A R882C mutations. Fragment analysis confirmed the previous results, and the variant allele ratio (VAR) for FLT3-ITD was $86 \%$ and $42 \%$ for NPM1 c.863_864ins (Figure 2).

The DNMT3A R882C and FLT3-D 835 (c.2504A $>$ T, D835V) mutations were also confirmed by capillary sequencing (Figure 3 ). Besides these two mutations, no other variations in the amplicon were found.

Taking into account that we found four somatic mutations in our patient we supposed that our AML case may also associate other abnormalities (which can be useful for the clinical management of the patient) we decided to perform NGS. After data analysis, we obtained five vari- 
Table I. PCR protocols used with locally adapted and optimized conditions

\begin{tabular}{|c|c|c|c|c|c|}
\hline & Primers & PCR conditions & & Digestion & Electrophoresis \\
\hline FLT3 ITD & $\begin{array}{l}\text { Fw: GCA ATT TAG GTA TGA } \\
\text { AAG CCA GC } \\
\text { Rev: CTT TCA GCA TTT TGA } \\
\text { CGG CAA CC }\end{array}$ & $\begin{array}{l}94^{\circ} \mathrm{C} 7 \mathrm{~min} \\
94^{\circ} \mathrm{C} 35 \mathrm{sec} \\
56^{\circ} \mathrm{C} 50 \mathrm{sec} \\
72^{\circ} \mathrm{C} 2 \mathrm{~min} \\
72^{\circ} \mathrm{C} 10 \mathrm{~min}\end{array}$ & x35 & - & $\begin{array}{l}\text { Wild type allele at } 327 \\
\text { bp } \\
\text { Mutant allele variable }\end{array}$ \\
\hline $\begin{array}{l}\text { FLT3 } \\
\text { D835 }\end{array}$ & $\begin{array}{l}\text { Fw: CCG CCA GGA ACG TGC } \\
\text { TTG } \\
\text { Rev: GCA GCC TCA CAT TGC } \\
\text { CCC }\end{array}$ & $\begin{array}{l}95^{\circ} \mathrm{C} 4 \mathrm{~min} \\
94{ }^{\circ} \mathrm{C} 35 \mathrm{sec} \\
56^{\circ} \mathrm{C} 35 \mathrm{sec} \\
72^{\circ} \mathrm{C} 45 \mathrm{sec} \\
72^{\circ} \mathrm{C} 10 \mathrm{~min}\end{array}$ & $\mathrm{x} 35$ & $\begin{array}{l}\text { Fast Digest } \\
\text { Eco21I (EcoRV) } \\
\text { enzyme } \\
20 \text { minutes at } 37 \\
{ }^{\circ} \mathrm{C}\end{array}$ & $\begin{array}{l}\text { Wild type allele at } 46 \\
\text { and } 68 \mathrm{bp} \\
\text { Mutant allele at } 114 \mathrm{bp}\end{array}$ \\
\hline $\begin{array}{l}\text { DNMT3A } \\
\text { R882 mu- } \\
\text { tations }\end{array}$ & $\begin{array}{l}\text { Fw: GTG ATC TGA GTG CCG } \\
\text { GGT TG } \\
\text { Rev: TCT CTC CAT CCT CAT } \\
\text { GTT CTT G }\end{array}$ & $\begin{array}{l}95^{\circ} \mathrm{C} 7 \mathrm{~min} \\
94{ }^{\circ} \mathrm{C} 35 \mathrm{sec} \\
60{ }^{\circ} \mathrm{C} 35 \mathrm{sec} \\
72^{\circ} \mathrm{C} 45 \mathrm{sec} \\
72^{\circ} \mathrm{C} 10 \mathrm{~min}\end{array}$ & x35 & $\begin{array}{l}\text { Fast Digest SsiI } \\
\text { (AciI) enzyme } \\
20 \text { minutes at } \\
37^{\circ} \mathrm{C} \text { - for both, } \\
\mathrm{R} 882 \mathrm{H} \text { and } \\
\text { R882C mutations } \\
\text { Fast Digest AluI - } \\
\text { for differentiation } \\
\text { of R882H and } \\
\text { R } 882 \mathrm{C} \text { mutation }\end{array}$ & $\begin{array}{l}\text { Wild type allele at } 125 \\
\text { and } 252 \mathrm{bp} \\
\text { Mutant allele at } 125, \\
252 \text { and } 303 \mathrm{bp} . \\
\text { Wild type allele at } \\
444 \mathrm{bp} \\
\text { R882H mutation like } \\
\text { wild type allele- } 444 \mathrm{bp} \\
\text { R882C mutation at } 444 \text {, } \\
250 \text { and } 194 \mathrm{bp} \text {. }\end{array}$ \\
\hline NPM1 & $\begin{array}{l}\text { Common (C): GGA AGT AAC } \\
\text { ATT GGC CAT ATG G } \\
\text { Normal (N) : TTC TTA AAG } \\
\text { AGA CTT CCT CCA CTG CC } \\
\text { For TCTG, TATG and CATG } \\
\text { insertion (A): TTC TTA AAG } \\
\text { AGA CTT CCT CCA CTG CC } \\
\text { For AGGA insertion (B): TCT } \\
\text { TAA AGA GAC TTC CTC CAC } \\
\text { TGC AGG AC } \\
\text { For TCTG insertion (D): TTC } \\
\text { TTA AAG AGA CTT CCT CCA } \\
\text { CTG CCA TGC }\end{array}$ & $\begin{array}{l}95^{\circ} \mathrm{C} 7 \mathrm{~min} \\
94^{\circ} \mathrm{C} 50 \mathrm{sec} \\
67^{\circ} \mathrm{C} 50 \mathrm{sec} \\
72^{\circ} \mathrm{C} 50 \mathrm{sec} \\
72^{\circ} \mathrm{C} 10 \mathrm{~min}\end{array}$ & $\mathrm{x} 35$ & - & $\begin{array}{l}\text { Wild type allele- ampli- } \\
\text { fication only for PCR } \\
\text { amplicon with N and C } \\
\text { primers (ARMS-PCR) } \\
\text { at } 337 \mathrm{bp} \\
\text { Mutant allele- amplifi- } \\
\text { cation for PCR ampli- } \\
\text { con with C and A, C and } \\
\text { B or C and D primers } \\
\text { (ARMS-PCR) at } 337 \text { bp }\end{array}$ \\
\hline $\begin{array}{l}\text { Multiplex } \\
\text { FLT3 } \\
\text { ITD and } \\
\text { NPM1- } \\
\text { for frag- } \\
\text { ment anal- } \\
\text { ysis }\end{array}$ & $\begin{array}{l}\text { FLT3 Fw FAM: AGCA ATT } \\
\text { TAG GTA TGA AAG CCA } \\
\text { GCTA } \\
\text { FLT3 Rev CTT TCA GCA TTT } \\
\text { TGA CGG CAA CC } \\
\text { NPM Fw: GTT TCT TTT TTT } \\
\text { TTT TTT CCA GGC TAT TCA } \\
\text { AG } \\
\text { NPM Rev HEX: CAC GGT } \\
\text { AGG GAA AGT TCT CAC } \\
\text { TCT GC }\end{array}$ & $\begin{array}{l}95^{\circ} \mathrm{C} 10 \mathrm{~min} \\
94{ }^{\circ} \mathrm{C} 50 \mathrm{sec} \\
60^{\circ} \mathrm{C} 50 \mathrm{sec} \\
72{ }^{\circ} \mathrm{C} 50 \mathrm{sec} \\
72{ }^{\circ} \mathrm{C} 10 \mathrm{~min} \\
\text { Hold } 4{ }^{\circ} \mathrm{C}\end{array}$ & $\mathrm{x} 35$ & - & $\begin{array}{l}\text { NPM1 wild type allele } \\
\text { at } 166 \text { bp and the mutant } \\
\text { allele at } 170 \mathrm{bp} \\
\text { FLT3 ITD wild type al- } \\
\text { lele at } 327 \text { bp } \\
\text { FLT3 ITD mutant allele } \\
\text { variable }\end{array}$ \\
\hline
\end{tabular}



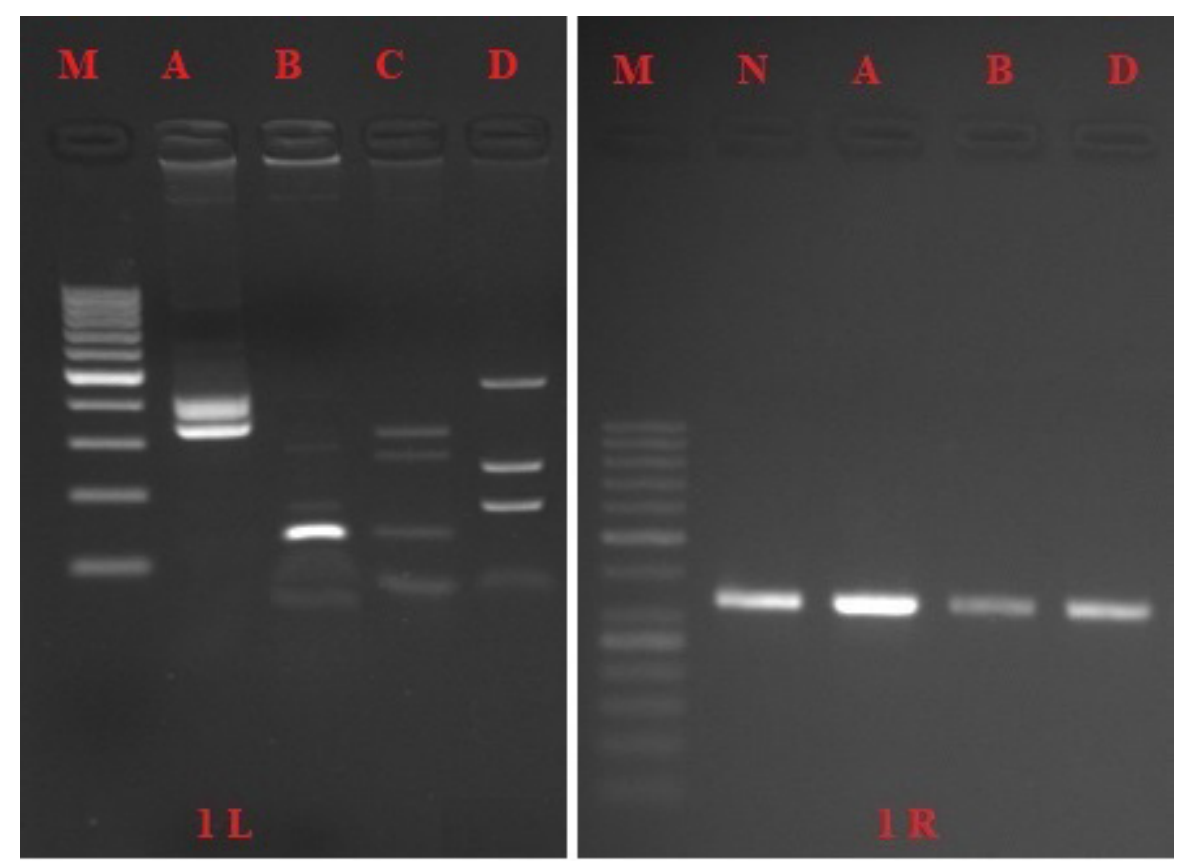

Fig. 1. Electrophoresis results for the somatic mutations investigated by PCR, RFLP-PCR and ARMS PCR. 1L- LEFT: M-Marker 100bp, A- FLT3 ITD heterozygous genotype, B-FLT3 D835 heterozygous genotype, C- DNMT3A with AciI enzyme- heterozygous genotype, D- DNMT3A with AluI enzyme- heterozygous genotype. 1R-RIGHT: M-Marker 50bp, N-normal primer, A- A primer (table I) and common primer, B- B primer and common primer, D- D primer and common primer.

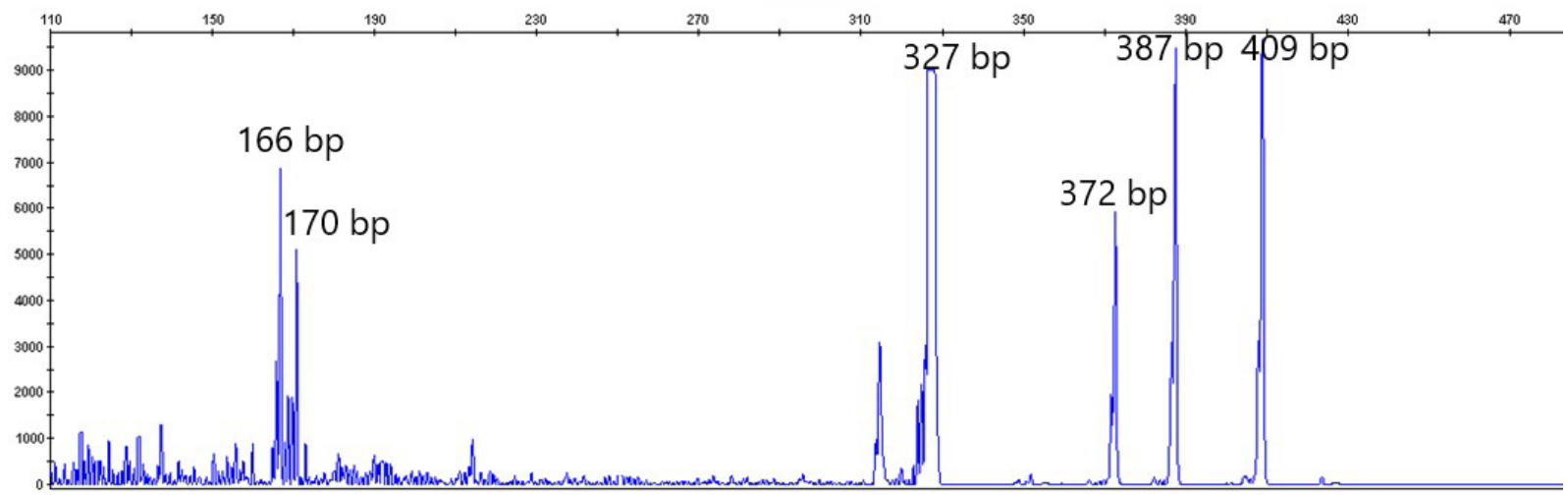

Fig. 2. Fragment analysis by capillary electrophoresis. At $166 \mathrm{pb}($ height $=6854)$ is the peak for the wild type NPM1 clone, at 170pb (height=5103) the peak for the NPM1 mutant clone. At 327pb (height=9005) the peak for the wild type FLT3-ITD clone and at 372pb (height=5910, 15 tandem duplications), 387 (height=9496, 20 tandem duplications) and at 409 (height=9672, 27 tandem duplications) the peaks for three different FLT3-ITD mutant clones. 

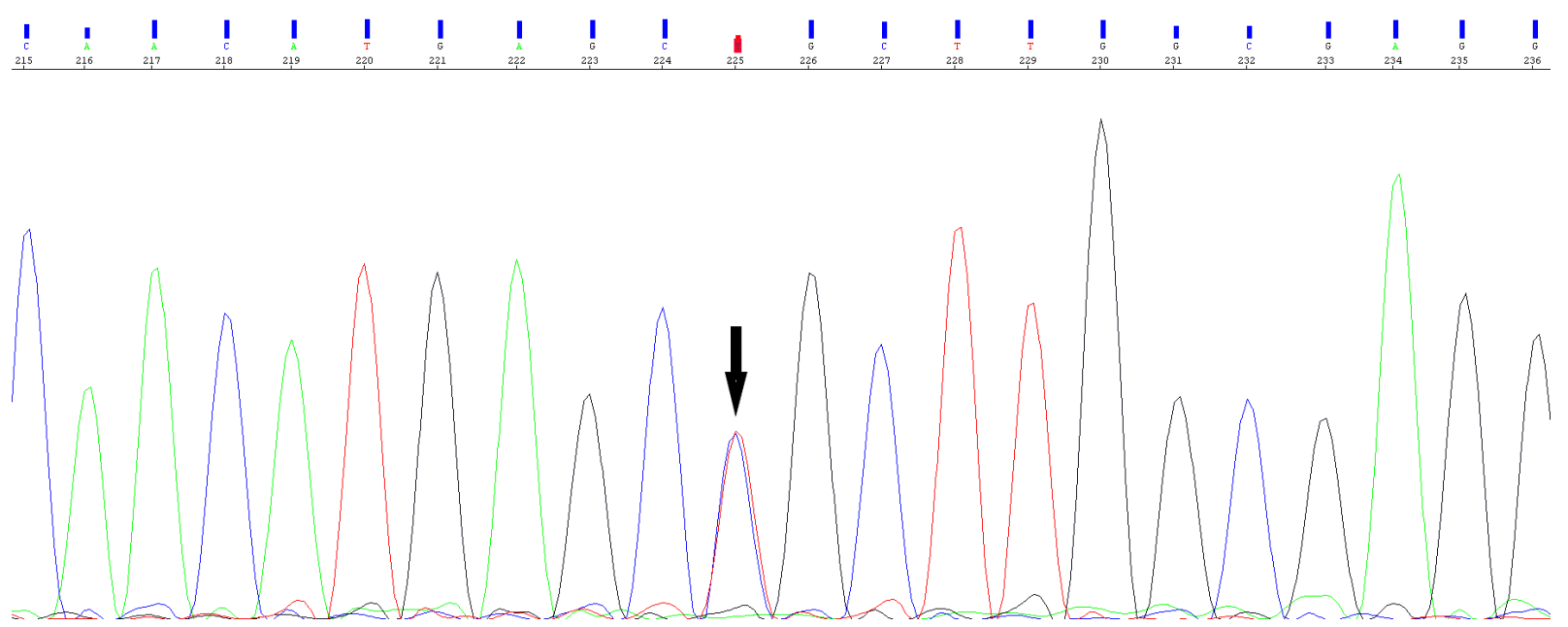

Fig. 3. Capillary sequencing results for DNMT3A R882C mutation. The position of the mutation is marked by "Y" in the DNA sequence results and also on the electropherogram (indicated by arrow).

ants: rs1042522 (homozygous genotype with the variant allele), rs377577594 (heterozygous genotype; VAR 41.5\%), rs2276599 (homozygous genotype with the variant allele), rs2454206 (heterozygous genotype) and rs587776806 (heterozygous genotype; VAR 42.86\%). After we consulted the databases, only rs377577594 (DNMT3A R882C mutation; VAR 41.5\%) and rs587776806 (NPM1 c.863_864insTCTG mutation; VAR $42.86 \%$ ) were with pathogenic/likely pathogenic significance (ClinVar, COSMIC and Ensembl genome browser with last data accessed on December 1, 2018). In the case of rs1042522 (TP53 c.215C >A, p.Pro72Leu) the clinical significance is uncertain for Li-Fraumeni syndrome and Hereditary cancer-predisposing syndrome. The clinical significance data for rs2276599 (DNMT3A c.666+7G>A. p.?) and rs2454206 (TET2 c.5284A>T, p.Ile1762Leu) are not available at the moment.

The last three variants, rs1042522, rs2276599 and rs2454206 were confirmed by TaqMan assays (ThermoFisher Scientific) and the 7500 Fast Dx Real-Time PCR system.

Additionally, the patient showed no CNAs fol- lowing the MLPA analysis (Figure 4).

\section{Discussions}

In this study, we briefly presented our proposed algorithm for the analysis of CNAs, aneuploidies and gene mutations focusing on a rare patient with AML. Our results showed that the patient had an intermediate risk according to the 2017 ELN risk stratification (FLT3-ITD ${ }^{\text {high }}$ and mutated NPM1). Based on our findings and according to the World health organization 2016 classification, we considered our case as AML with recurrent genetic abnormalities [6]. Even though the previously described PCR and ARMS-PCR protocols $[12,14]$ are easy to use, inexpensive and can be performed with basic infrastructure, we recommend the fragment analysis for FLT3-ITD and NPM1 c.863_864ins, the biggest advantage being the possibility to quantify the mutant clone and monitor its dynamics over time. For NPM1 c.863_864ins, neither ARMSPCR [14] nor fragment analysis can distinguish between the inserted oligonucleotides, therefore being unable to specify the type of NPM1 mu- 


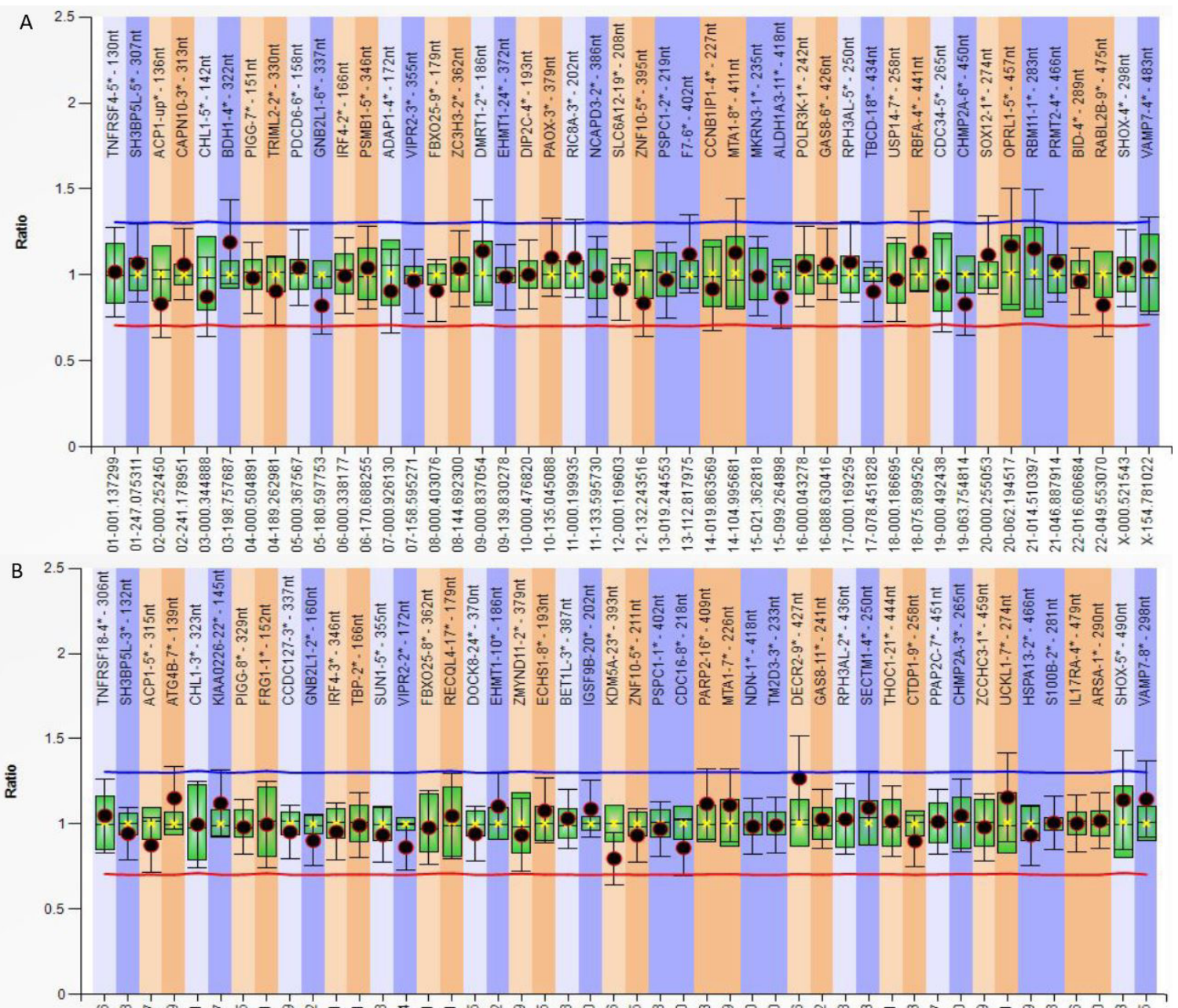

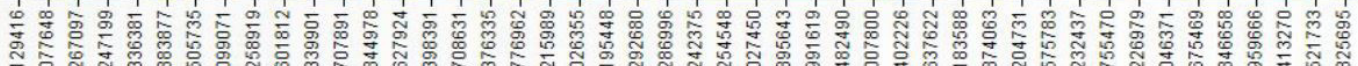

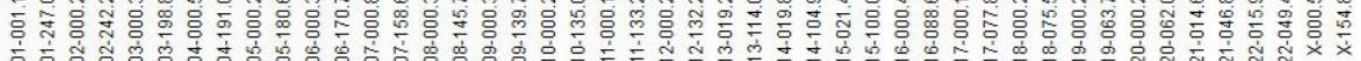

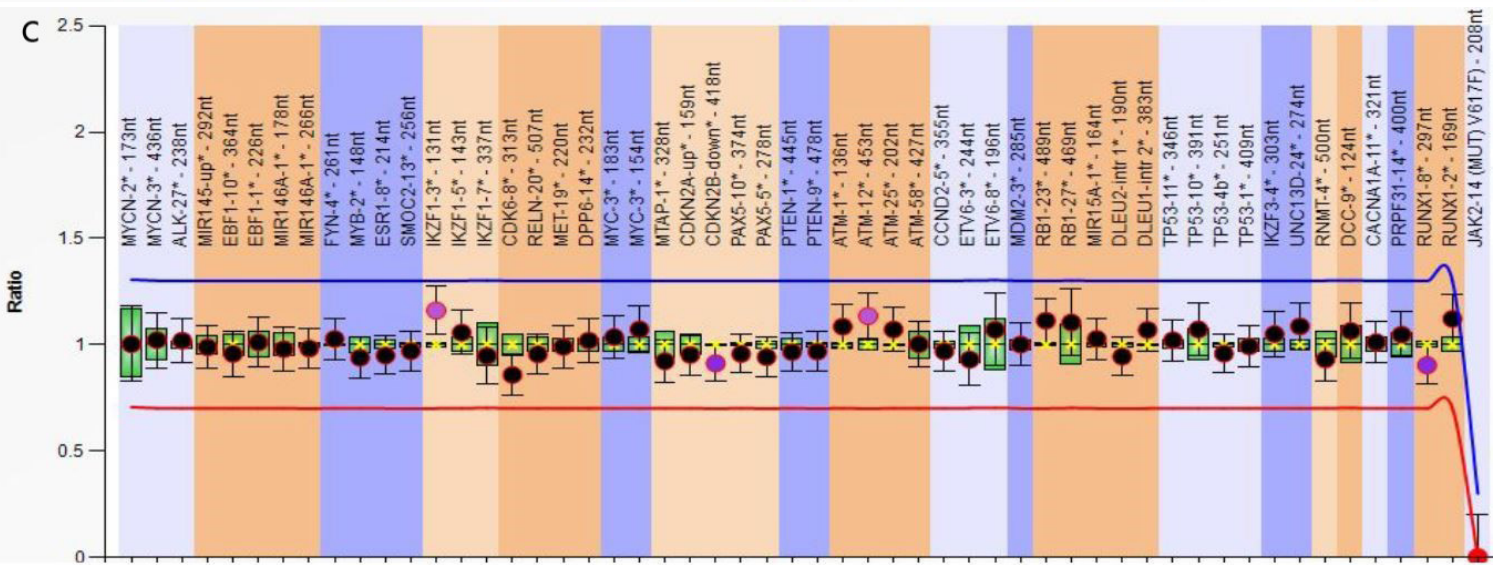

Fig. 4. MLPA results illustrated by Ratio chart. A- for P036 probemix; B- for P070 probemix, Cfor P337 probemix 
tation. However, from a clinical point of view, all NPM1 mutations, types A-D, have the same clinical significance. Type of NPM1 mutation was revealed by NGS. Similarly, the exact type of FLT3-D835, cannot be identified by RFLPPCR but as with NPM1 mutations, all of them have the same clinical significance. In this case, the sequencing performed for FLT3-D835 confirmation revealed the exact mutation, namely c. $2504 \mathrm{~A}>\mathrm{T}, \mathrm{D} 835 \mathrm{~V}$.

The patient investigated by us presented four somatic mutations, FLT3-ITD and D835V, DNMT3A R882C, and NPM1 c.863_864insTCTG. Frequently, these mutations occur concomitantly, but patients positive for all four of them are rare. According to our present knowledge, none have been previously described in literature. One study performed on $100 \mathrm{AML}$ patients revealed no FLT3+DNMT3A+NPM1 positive cases [17], and FLT3-D835 mutation was not determined. Loghavi et al. (2014) concluded that AML patients with $N P M 1+D N M T 3 A$ mutations had a shorter overall and event-free survival compared with FLT3-ITD $+N P M 1$ positive patients. FLT3-ITD $+N P M 1+D N M T 3 A$ positive patients (18 from 178 AML patients, FLT3-D835 mutation unevaluated) presented the worst clinical outcomes in another clinical study [18]. The clinical implications of the above mentioned mutations (FLT3-ITD $+N P M 1+D N M T 3 A$ positive patients with or without FLT-D835) remain poorly understood [17-20].

Unfortunately, targeted treatment with FLT3 inhibitors could not be initiated in our patient because he died three days after the diagnosis. We respected the ELN recommendations and the current diagnostic guidelines, the patient being tested for both (FLT3-ITD and D835 and not only) in parallel with cytogenetic analysis, and the molecular results (MLPA analysis and somatic mutations analysis) were handed to the Hematological Clinic in three days. Even so, the patient's evolution was not favorable. For these reasons, it is very important to have a clinical diagnosis as soon as possible.

As Loghavi et al. [18] reported, FLT3-ITD+FLT3-D835+NPM1+DNMT3A positive AML patients seem to have the worst clinical outcomes.

From our point of view, cytogenetics, MLPA, FLT3-ITD and NPM1 (investigated by fragment analysis), DNMT3A and FLT3-D835 (analyzed by RFLP-PCR) are mandatory for AML patients and in order to initiate the FLT3 inhibitors were necessary, the clinical diagnosis must be performed in the shortest possible time. As Coriu et al. [21] previously reported, NGS technology is a promising technique for AML patients having the advantage of extensive data evaluation, high sensitivity and quantitation of detected mutations [21]. This versatile technology based on highly multiplexed PCR allows us to investigate different loci which are very difficult to analyze with other techniques (for example $C E B P A$ gene) [22]. In our case, two known mutations were confirmed and three other variants were found. As we previously mentioned, currently, data regarding clinical significance are not available for rs2276599 and rs2454206. Therefore it is essential to report the data obtained by NGS in order to clarify its clinical significance.

Real-time TaqMan technology used in the present research and also in case-control studies can be a versatile, fast and inexpensive technique for the clinical interpretation of obtained results.

In conclusion, all these techniques can be useful in the diagnosis of AML patients, each of them covering the limits of the other technique. Taking into account the clinical impact of these genetic abnormalities in AML patients, new strategies for a positive, fast, accurate and reliable diagnosis are mandatory.

\section{Author contribution}

TF, BC designed the study, performed MLPA analysis and results interpretation. TF wrote the 
manuscript. BA and $\mathrm{BC}$ performed cytogenetic analysis and interpretation. TF, CG, BA, MV, $\mathrm{BC}$ performed somatic mutations analysis, NGS analysis and data interpretation. LE, BI Jr. collected the data, blood and bone marrow samples. LE and BC performed the critical revision of the paper. All authors read and approved the final version of the manuscript.

\section{Conflict of interest}

None to declare.

\section{Acknowledgement}

This work was supported by the University of Medicine, Pharmacy, Science, and Technology of Târgu Mureş, Romania, Research Grant number 15609/13/29.12.2017.

\begin{abstract}
Abbreviation
AML-Acute myeloid leukemia, CNAs-Copy number aberrations, CNVs-Copy number variations, DNMT3A-DNA methyltransferase 3A gene, ELN-European LeukemiaNet, FISH-Fluorescent in situ hybridization, FLT3-FMS-like Tyrosine Kinase 3, MLPA-Multiplex Ligation-dependent Probe Amplification, NPM1-Nucleophospmin 1, VAR-Variant allele ratio.
\end{abstract}

\section{References}

1. Bănescu C, Iancu M, Trifa AP, Dobreanu M, Moldovan VG, Duicu C et al. Influence of XPC, XPD, XPF, and $\mathrm{XPG}$ gene polymorphisms on the risk and the outcome of acute myeloid leukemia in a Romanian population. Tumour Biol. 2016;37(7):9357-66. DOI: 10.1007/ s13277-016-4815-6

2. Arber DA. Acute myeloid leukemia, in His Eric D (Eds), Hematopathology, 3nd Ed, Elsevier Philadelphia, 2019, 429-466. DOI: 10.1016/B978-0-323-47913-4.00030-6.

3. Bullinger L, Döhner K, Döhner H. Genomics of Acute Myeloid Leukemia Diagnosis and Pathways. J Clin Oncol. 2017;35(9):934-46. DOI: 10.1200/ JCO.2016.71.2208

4. Bănescu C, Iancu M, Trifa AP, Cândea M, Benedek Lazar E, Moldovan VG et al. From Six Gene Poly- morphisms of the Antioxidant System, Only GPX Pro198Leu and GSTP1 Ile105Val Modulate the Risk of Acute Myeloid Leukemia. Oxid Med Cell Longev. 2016;2016:2536705. DOI: 10.1155/2016/2536705

5. Antohe I, Dăscălescu A, Dănăilă C, Zlei M, Ivanov I, Sireteanu A, et al. FLT-3 ITD Positive Acute Basophilic Leukemia with Rare Complex Karyotype Presenting with Acute Respiratory Failure: Case Report. Rev Romana Med Lab. 2018;26(1):87-94. DOI: 10.1515/rrlm2017-0036

6. Arber DA, Orazi A, Hasserjian R, Thiele J, Borowitz MJ, Le Beau MM et al. The 2016 revision to the World Health Organization classification of myeloid neoplasms and acute leukemia. Blood. 2016;127(20):2391405. DOI: 10.1182/blood-2016-03-643544

7. Döhner H, Estey E, Grimwade D, Amadori S, Appelbaum FR, Büchner T et al. Diagnosis and management of AML in adults: 2017 ELN recommendations from an international expert panel. Blood.2017;129(4):424-47. DOI: 10.1182/blood-2016-08-733196

8. Crauciuc GA, Tripon F, Bogliş A, Făgărăşan A, Bănescu C. Multiplex ligation dependent probe amplification - A useful, fast and cost-effective method for identification of small supernumerary marker chromosome in children with developmental delay and congenital heart defect. Rev Romana Med Lab. 2018;26(4):461-70. DOI: $10.2478 / \mathrm{rrlm}-2018-0032$

9. Bogliş A, Tripon F, Bănescu C. The utility of molecular genetic techniques in craniosynostosis cases associated with intellectual disability. Rev Romana Med Lab. 2018;26(4):471-7. DOI: 10.2478/rrlm-2018-0033

10. Vázquez-Reyes A, Bobadilla-Morales L, Barba-Barba C, Macías-Salcedo G, Serafín-Saucedo G, Velázquez-Rivera ME et al. Aneuploidy identification in pre-B acute lymphoblastic leukemia patients at diagnosis by Multiplex Ligation-dependent Probe Amplification (MLPA). Leuk Res. 2017;59:117-23. DOI: 10.1016/j.leukres.2017.05.022

11. Oltean A, Chincesan MI, Marginean O, Horvath E. Myelodysplastic syndrome with myelofibrosis in a 12-year-old patient - A case report. Rev Romana Med Lab. 2018;26(1):95-103. DOI: 10.1515/rrlm-20170034

12. Moreno I, Martín G, Bolufer P, Barragán E, Rueda E, Román J et al. Incidence and prognostic value of FLT3 internal tandem duplication and D835 mutations in acute myeloid leukemia. Haematologica. 2003;88(1):19-24.

13. Brewin JN, Horne GA, Bisling KE, Stewart HJ, Chevassut TJ. Rapid detection of DNMT3A R882 codon mutations allows early identification of poor risk patients with acute myeloid leukemia. Leuk Lymphoma. 2013;54(6):1336-9. DOI: 10.3109/10428194.2012.736986

14. Azari-Yam A, Bagheri SD, Tavakkoly-Bazzaz J, Sarhaddi $\mathrm{AB}$, Rejali L, Alimoghaddam K et al. NPM1 
Mutation Detection in Acute Myeloid Leukemia: A Method Comparison Study. Genet Test Mol Biomarkers. 2016;20(2):63-6. DOI: 10.1089/gtmb.2015.0184

15. Huang Q, Chen W, Gaal KK, Slovak ML, Stein A, Weiss LM. A rapid, one step assay for simultaneous detection of FLT3/ITD and NPM1 mutations in AML with normal cytogenetics. Br J Haematol. 2008;142(3):48992. DOI: $10.1111 / \mathrm{j} .1365-2141.2008 .07205 . \mathrm{x}$

16. Negura L, Negura A. Sanger sequencing of MMR genes in a one-plate system. Rev Romana Med Lab. 2018;26(2):153-63. DOI: 10.2478/rrlm-2018-0008

17. Mevatee P, Tantiworawit A, Traisathit P, Puaninta C, Mevatee U, Angsuchawan S et al. FLT3-ITD, NPM1, and DNMT3A Gene Mutations and Risk Factors in Normal Karyotype Acute Myeloid Leukemia and Myelodysplastic Syndrome Patients in Upper Northern Thailand. Asian Pac J Cancer Prev. 2017;18(11):30319. doi:10.22034/APJCP.2017.18.11.3031.

18. Loghavi S, Zuo Z, Ravandi F, Kantarjian HM, Bueso-Ramos C, Zhang L et al. Clinical features of de novo acute myeloid leukemia with concurrent DNMT3A, FLT3 and NPM1 mutations. J Hematol Oncol.
2014;7:74. DOI: 10.1186/s13045-014-0074-4

19. Im AP, Sehgal AR, Carroll MP, Smith BD, Tefferi A, Johnson DE et al. DNMT3A and IDH mutations in acute myeloid leukemia and other myeloid malignancies: associations with prognosis and potential treatment strategies. Leukemia. 2014 ;28(9):1774-83. DOI: 10.1038/leu.2014.124

20. Cagnetta A, Adamia S, Acharya C, Patrone F, Miglino $\mathrm{M}$, Nencioni A et al. Role of genotype-based approach in the clinical management of adult acute myeloid leukemia with normal cytogenetics. Leuk Res. 2014, 38(6):649-59. DOI: 10.1016/j.leukres.2014.03.006

21. Coriu D, Jardan D, Jardan C, Tălmaci R, Dragomir M, Coliţă A. A new assay to identify recurrent mutations in acute myeloid leukemia using next-generation sequencing. Rev Romana Med Lab. 2014;22(1):93-9. DOI: $10.2478 / \mathrm{rrlm}-2014-0003$

22. Ahn JY, Seo K, Weinberg O, Boyd SD, Arber DA. A comparison of two methods for screening CEBPA mutations in patients with acute myeloid leukemia. J Mol Diagn. 2009;11(4):319-23. DOI: 10.2353/ jmoldx.2009.080121 